\title{
Unequal access to ART: exploratory results from rural and urban case
} studies of ART use

\author{
Susan May Cleary, ${ }^{1}$ Stephen Birch, ${ }^{1,2,3}$ Mosa Moshabela,4 Helen Schneider5
}

\begin{abstract}
${ }^{1}$ Health Economics Unit, School of Public Health and Family Medicine, University of Cape Town, Cape Town, South Africa ${ }^{2}$ Centre for Health Economics and Policy Analysis, McMaster University, McMaster, Canada 3School of Community Based Medicine, University of Manchester, UK 4Rural AIDS and Development Action Research, School of Public Health, University of Witwatersrand, Johannesburg, South Africa

5School of Public Health, University of Western Cape, Cape Town, South Africa
\end{abstract}

\section{Correspondence to}

Professor Susan May Cleary, Health Economics Unit, University of Cape Town, Anzio Road, Observatory, Cape Town 7925, South Africa; susan.cleary@uct.ac.za

\begin{abstract}
Introduction South Africa has the world's largest antiretroviral treatment (ART) programme. While services in the public sector are free at the point of use, little is known about overall access barriers. This paper explores these barriers from the perspective of ART users enrolled in services in two rural and two urban settings.

Methods Using a comprehensive framework of access, interviews were conducted with over 1200 ART users to assess barriers along three dimensions: availability, affordability and acceptability. Summary statistics were computed and comparisons of access barriers between sites were explored using multivariate linear and logistic regressions.
\end{abstract}

Results While availability access barriers in rural settings were found to be mitigated through a more decentralised model of service provision in one site, affordability barriers were considerably higher in rural versus urban settings. 50\% of respondents incurred catastrophic healthcare expenditure and $36 \%$ borrowed money to cover these expenses in one rural site. On acceptability, rural users were less likely to report feeling respected by health workers. Stigma was reported to be lowest in the two sites with the most decentralised services and the highest coverage of those in need.

Conclusions While results suggest inequitable access to ART for rural relative to urban users, nurse-led services offered through primary healthcare facilities mitigated these barriers in one rural site. This is an important finding given current policy emphasis on decentralised and nurseled ART in South Africa. This study is one of the first to present comprehensive evidence on access barriers to assist in the design of policy solutions.

\section{BACKGROUND}

Southern Africa has approximately 34\% of the world's HIV-infected people, half of whom live in South Africa. ${ }^{1}$ In 2003, the South African government introduced antiretroviral treatment (ART) free at the point of use in selected public health facilities. Between 2003 and the end of 2009, approximately 1 million adults and children were enrolled onto ART. While this is a considerable achievement, coverage of those in need ranged between $37 \%$ and $56 \%$ in 2009 (depending on the 
definition of need); between 2003 and mid-2009, it is estimated that 2.4 million people died from HIV- related causes, many of whom would not have had access to ART.1-4

In the 2007 'HIV \& AIDS and STI National Strategic Plan',5 the South African government committed to providing 'an appropriate package of treatment, care and support services to $80 \%$ of people living with HIV. by 2011' (p. 64).

However, there are no commitments to ensuring that access to treatment reaches the poor and those in rural areas during the period of scale-up. The inverse equity hypothesis suggests that the introduction of new interventions might lead to a paradoxical worsening of health equity as those in urban areas and those of higher socioeconomic status (SES) might initially have better access to the service. Because of this, some have called for the specific inclusion of health equity targets within overall HIV treatment targets so that progress on this front can be monitored. ${ }^{6}$

The South African government has recently acknowledged that the availability of ART services in urban informal settlements (where poverty is pervasive and HIV prevalence is highest) and in rural areas has been limited, and plans to address these inequities in resource allocation. ${ }^{3}$ At the time of writing, ART has been offered from approximately 500 public healthcare facilities, predominantly hospitals and community health centres. To increase availability, government intends to decentralise provision to enable all of the country's 4000 public facilities to initiate patients on ART through a process of task shifting from physicians to nurses.3 Increased availability may also allow for patients to initiate ART before they become severely immune compromised. Delayed initiation of ART is associated with a higher risk of death, a higher incidence of tuberculosis and opportunistic infections and higher costs of treatment.7

Increasing coverage and ensuring retention in care require a context-specific understanding and response to the barriers to access and use. While improving access to healthcare is a frequently identified goal of health policy, there is still debate about the precise meaning of the term. In the earlier literature, access was primarily viewed in terms of two factors-money fees at the point of use and distance travelled to use care. Others have defined access in terms of service use or coverage, perhaps because this is easier to quantify. ${ }^{8}$ More recently, access has been defined as the empowerment of an individual to use healthcare, a multidimensional notion based on the degree of fit between healthcare systems, individuals, households and communities. Under this conceptual framework, the three dimensions of access are availability (or physical access), affordability (or financial access) and acceptability (or cultural access). 9 These dimensions are argued to act as a starting point for empirically investigating access and for developing heath policy strategies that can address these barriers. ${ }^{10}$

Despite the importance of enhancing access to ART, very little research has been conducted regarding the barriers faced by individuals using ART services. A recent review found only six studies on this topic in developing countries published in the peer-reviewed literature. ${ }^{11}$ The review concluded that lack of awareness, stigma, affordability and distance to the health facility were the key barriers and commented on the lack of studies comparing access barriers between rural and urban areas. 
This study unpacks the barriers to accessing ART through two rural and two urban case studies of adults using ART in South Africa. Findings from the study may provide evidence to assist government in designing policies to improve health equity between geographic locations.

\section{METHODS}

\section{Conceptual framework of access}

This study draws on a comprehensive conceptual framework of access where access is viewed as the degree of fit between population needs and health system responses in terms of affordability (fit between costs of utilising the service and household ability to pay), availability (fit between patient needs and the type, place and time of services provided) and acceptability (fit between provider and patient attitudes towards and expectations of each other). 9 10 Following Braveman, ${ }^{12}$ inequitable access arises if barriers are systematically different for individuals with different levels of social advantage, including with reference to their geographical location. In other words, if the fit between healthcare costs and household ability to pay is less favourable in rural areas, then this is evidence of inequitable access to ART. This could arise, for example, if the travel distance and the transport costs incurred to reach health facilities in rural areas were higher than in urban areas. However, if such additional burdens on the household budget of rural dwellers were mitigated through travel vouchers or social grants, then this would not necessarily be evidence of inequities because these barriers would have been reduced through increasing the household's ability to pay.

Each access dimension is captured by a number of variables, examples of which are outlined in table 1. Availability variables include the travel time to reach the ART facility, the mode of travel and the time spent at the clinic during the previous clinical consultation. Affordability variables include whether or not the respondent was receiving a government chronic care (disability) grant (R10oo per month). This grant is available to individuals who are not able to work owing to illness and who have an annual income below a certain threshold (R29 112 for single people or R58224 for married people). At the time of this study, low-income patients starting ART qualified to receive this grant for a 6-month period. In addition, information on healthcare expenditure was collected including the costs incurred during the current ART clinic visit (transport, someone to take over tasks including childcare, accommodation if necessary, food during the visit and telephone costs). These costs were converted to monthly expenditure estimates using information on the reported frequencies of ART clinic visits. Respondents were also asked about 'self-care' expenditure that they had incurred during the previous month (eg, costs of special food and over the counter medicines or vitamins, costs of buying traditional medicines) as well as any expenditure that they had incurred through seeking additional care from other providers (including general practitioners in the private sector, traditional healers, etc). By contrasting these costs with overall household expenditure, catastrophic expenditure-defined as expenditure on healthcare exceeding $10 \%$ of household expenditure ${ }^{13}$-was assessed. We also asked respondents whether they had needed to borrow money to cover these costs. 
Table 1 Dimensions of access

\begin{tabular}{|c|c|c|}
\hline Availability & Affordability & Acceptability \\
\hline $\begin{array}{l}\text { Mode and cost } \\
\text { of transport } \\
\text { Travel time to } \\
\text { facility } \\
\text { Waiting time } \\
\text { at facility }\end{array}$ & $\begin{array}{l}\text { Overall expenditure on } \\
\text { healthcare (including } \\
\text { expenditure to reach } \\
\text { ART facility, expenditure } \\
\text { on self-care and expenditure } \\
\text { on other providers) } \\
\text { Healthcare costs as a } \\
\text { proportion of household } \\
\text { expenditure } \\
\text { Needing to borrow money } \\
\text { to pay for healthcare expenses } \\
\text { Receipt of government } \\
\text { 'disability' grants }\end{array}$ & $\begin{array}{l}\text { Perceptions of staff attitudes, } \\
\text { facility cleanliness, length of } \\
\text { queues and community } \\
\text { judgement (as a proxy for } \\
\text { stigma) }\end{array}$ \\
\hline
\end{tabular}

Adapted from Thiedeef $a /{ }^{10}$.

ART, antiretroviral treatment.

In terms of acceptability, we asked respondents to report their perceptions of staff attitudes ('Some staff do not treat patients with sufficient respect'), cleanliness ('The facilities (including waiting areas and toilets) are dirty'), the length of queues ('The queues to see a doctor or nurse are too long at this facility') and perceptions of stigma ('Do you feel that people in the community judge you negatively for attending this facility for your ARV treatment?').

\section{Setting and participants}

Four sub-districts were purposively selected from four provinces representing two metropolitan urban (Soweto in the City of Johannesburg, Gauteng Province and Mitchells Plain in the Cape Metropole, Western Cape Province) and two deep rural settings (Hlabisa in Northern KwaZulu Natal and Bushbuckridge in Mpumalanga Province). These sites also present a mixed picture with respect to models of ART care-from decentralised nurse- based provision in one rural site (Hlabisa) to a prominent tertiary hospital-based service in one urban sub-district (Soweto). Table 2 documents contextual differences between sub-districts. HIV prevalence at the district level has also been documented, although it should be borne in mind that there may be a great deal of heterogeneity in each district and these results may not be applicable to the sub-district population. However, based on these estimates together with population size and numbers on ART, Bushbuckridge can be classified as low, Hlabisa as high, Soweto as medium and Mitchells Plain as high in terms of the coverage of those in need of ART.

A representative sample of 1267 ART users was interviewed within 12 ART facilities across the four settings (approximately 300 respondents per setting). In each sub-district, all accredited facilities were included where possible, and where multiple facilities existed, self-weighting stratified, proportional or probability proportional to size methods were used to select facilities using data on the total number of users in each facility at the time of the research. Within facilities, systematic random sampling methods were used to choose respondents. An interviewer-administered questionnaire was designed to collect socioeconomic and demographic data as well as information regarding key barriers to accessing ART from the perspective of ART 
users. Subjects were included if they had been taking ART for at least 14 days, were over the age of 18 and were judged sufficiently well by clinical staff to be interviewed. After obtaining written informed consent to participate in the study, the interview was conducted by trained fieldworkers in the language of each subject's choice. Ethical approval for the study was granted by committees at the Universities of Cape Town, Witwatersrand and KwaZulu-Natal. Further permission to conduct the research was obtained from provincial and local health authorities.

Table 2 Profile of each sub-district: population, type of service provision (centralised, decentralised), number of people on ART at time of research

\begin{tabular}{|c|c|c|c|c|}
\hline 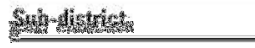 & 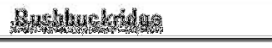 & Mhaisat & 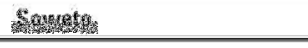 & 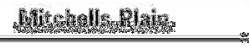 \\
\hline 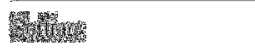 & 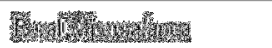 & 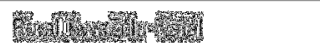 & 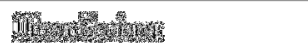 & 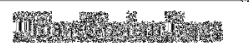 \\
\hline 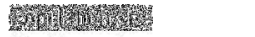 & 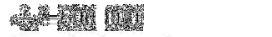 & 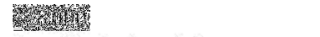 & 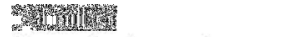 & 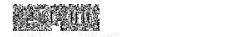 \\
\hline Health service & $\begin{array}{l}\text { One district and one } \\
\text { regional hospital } \\
\text { One CHC } \\
83 \text { PMC clinics }\end{array}$ & $\begin{array}{l}\text { One district hospital } \\
15 \text { PHC clinics }\end{array}$ & $\begin{array}{l}\text { One national central } \\
\text { and one TB hospital } \\
\text { Five CHCs } \\
26 \text { PHC clines }\end{array}$ & $\begin{array}{l}\text { Three CHC } \\
\text { 10 PHC dinics }\end{array}$ \\
\hline 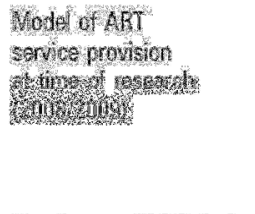 & 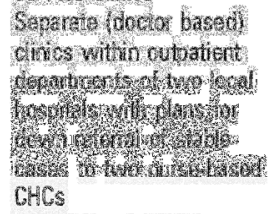 & 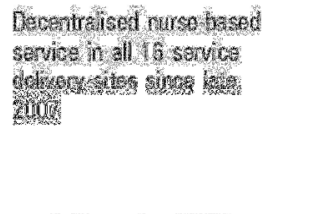 & 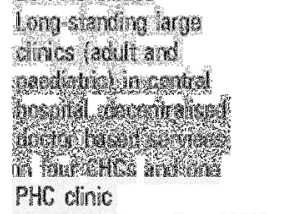 & $\begin{array}{l}\text { Dootor based services } \\
\text { in tried CHCs }\end{array}$ \\
\hline Mumbers on ART (date) & 3900 (March 2000) & 7576 (0ocember 2008) & \pm 28500 \{[acenber 2009 \} & 4843 (0ctobar 2008) \\
\hline WW previence in & 34 9\% Fblargeni district & 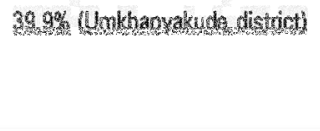 & 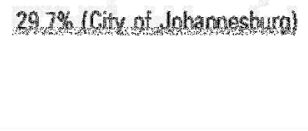 & 17.96 1Cane Marrnole \\
\hline
\end{tabular}

\section{Data analysis}

Completed questionnaires were checked for accuracy by a data collection coordinator and double entered into a data entry platform specifically designed for this purpose in EpiData V $3 .{ }^{14}$ Data were then exported to Stata/IC 11.0 for analysis. We used as asset index approach to estimate the SES of respondents. While some argue that SES is best measured by household income, consumption or expenditure, these data are often difficult to collect and are seldom available in developing countries. ${ }^{15}$ In a nutshell, the asset index approach seeks to allocate individuals to socioeconomic classes based on household characteristics (including type of house, walls, toilet facility, roof, water supply, electricity for cooking, etc) and assets (including fridge, stove, DVD player, television, cellphone, bicycle, etc). We constructed the index through performing a multiple correspondence analysis. While the construction of SES indices is commonly achieved using principal components analysis, ${ }^{16}$ such a technique is more appropriate for use with continuous normally distributed data as opposed to the predominantly categorical data often used in SES indices development. ${ }^{17}$

Summary statistics were used to compute average scores for each access variable, by site, and multivariate logistic and linear regressions were used to test for differences in access after controlling for socioeconomic (asset index, employment status, education) and demographic (sex) characteristics. This allowed for us to focus specifically on the site-level (rural/urban) access barriers and to test for inequalities in these barriers between sites, after holding other measures of social disadvantage constant. We also controlled for baseline CD4 count at the commencement of ART and time since commencement of ART. These were felt to be relevant in that sicker/healthier patients, and those on ART for shorter/longer might face different access 
barriers. For example, stigma might be a higher barrier initially, while affordability barriers might be compounded over time. Skewed quantitative variables were logged before inclusion in multivariate analysis.

\section{RESULTS}

Table 3 documents key socioeconomic and demographic variables by site. Rural respondents had lower SES than urban respondents. The asset index indicated that $73 \%$ and $86 \%$ of respondents in rural Bushbuckridge and Hlabisa, respectively, fell into the poorest 50\%, in contrast with $17 \%$ and $30 \%$ in urban Soweto and Mitchells Plain, respectively. Similarly, $17 \%$ and $12 \%$ of respondents in Bushbuckridge and Hlabisa were employed compared with $28 \%$ and $31 \%$ in Soweto and Mitchells Plain. Rural respondents also had lower mean number of years of education. While the baseline CD4 count was similar across sites, respondents in urban Mitchells Plain had spent less time on ART.

Table 3 Socio-demographics and bealth status by site

\begin{tabular}{|c|c|c|c|c|c|}
\hline & 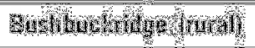 & Nisbisa (ural & Sowome artatis & 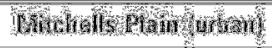 & Whatu \\
\hline 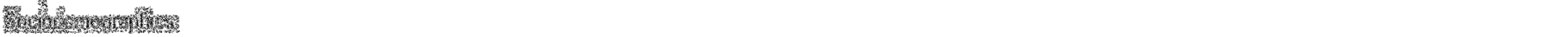 & 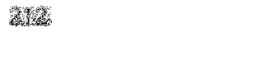 & 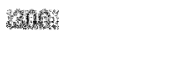 & 露知 & 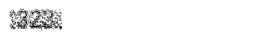 & \\
\hline ᄀ T P & 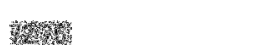 & rotorion & 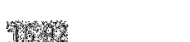 & 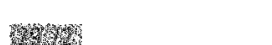 & 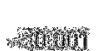 \\
\hline Respondent employed (\%) & 17.31 & 12.00 & 28.05 & 30.96 & $<0.001$ \\
\hline Mean (median) years of schooling & $7.3(8)$ & $6.6(7)$ & $9.4(10)$ & $9.2(10)$ & $<0.001$ \\
\hline 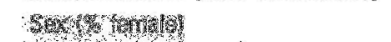 & (5) $5 \%$ & 6ou & 3068 & 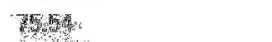 & : \\
\hline 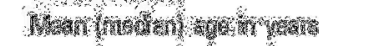 & $3 / 28$ & 63 & $66 x_{1}$ & 20 & \\
\hline \multicolumn{6}{|c|}{ Bh } \\
\hline 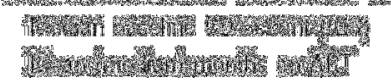 & 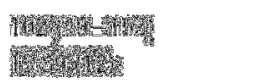 & 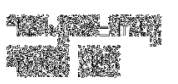 & 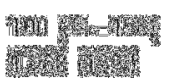 & 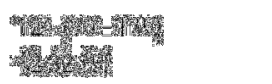 & 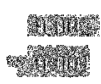 \\
\hline
\end{tabular}

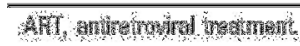

Table 4 presents the site-level results on each of the access variables included in this analysis. The results of multivariate regressions are shown as adjusted ORs or coefficients. Using rural Bushbuckridge as the referent, these results summarise differences between Bushbuckridge and the other sites across each dependent access variable, after controlling for SES (asset index), sex, years of education, employment status (employed or not), time on treatment and baseline health status (CD4 count).

\section{Availability}

In terms of availability (table 4 and figure 1), rural users on average spent more time travelling to the facilities than urban users. These findings, however, may have less to do with the setting and more to do with the service delivery model. Thus, while availability barriers were highest in rural Bushbuckridge across most variables, it is noteworthy that the model of decentralised service provision in the Hlabisa site suggests the potential to overcome many of these barriers in rural areas. For example, it could be argued that the ability to reach the facility by foot indicates that the services are located close to the homes of respondents. Here, $32.4 \%$ and $32.1 \%$ of respondents from rural Hlabisa and urban Mitchells Plain, respectively, reported travelling by foot to the facility. These two sites were also characterised by higher coverage of those in need and a more decentralised model of service provision (table 2). Once at the facility, respondents spent over 3.5 $\mathrm{h}$, with similar waiting times across most settings, with the exception of Mitchells Plain where mean waiting times were higher. 


\begin{tabular}{|c|c|c|c|c|c|c|c|c|}
\hline & \multicolumn{2}{|c|}{$\begin{array}{l}\text { Bushhurkrialge } \\
\text { Kurall }\end{array}$} & \multicolumn{2}{|c|}{ Habis (mual) } & \multicolumn{2}{|c|}{ Shoretn Juthan! } & \multicolumn{2}{|c|}{ Whitchells Pain ( } \\
\hline & $\begin{array}{l}\text { Nieanl } \\
\text { percesen }\end{array}$ & $\begin{array}{l}\text { Aory } \\
\text { Couef }\end{array}$ & $\begin{array}{l}\text { Baan } \\
\text { parcent }\end{array}$ & $\begin{array}{l}\text { Monchen: } \\
95 \% \text { c1) }\end{array}$ & $\begin{array}{l}\text { Nean/ } \\
\text { vercent: }\end{array}$ & $\begin{array}{l}\text { AMT traef } \\
195 \% \text { cil }\end{array}$ & $\begin{array}{l}\text { Mead } \\
\text { percent }\end{array}$ & $\begin{array}{l}\text { 40016net } \\
85 \% \text { Cil }\end{array}$ \\
\hline \multicolumn{9}{|l|}{ Availability } \\
\hline 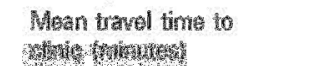 & 74.94 & $\neq$ & 66.40 & 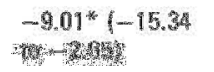 & 33.23 & $\begin{array}{l}-39.21 *\{-46.14 \\
6-3228\end{array}$ & 23.48 & $\begin{array}{l}-49.43^{*}(-56.09 \\
17-4.72)\end{array}$ \\
\hline 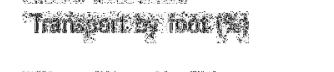 & 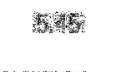 & 䇾 & s24.4: & 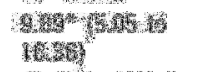 & 7y: & 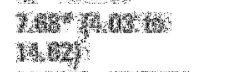 & arets & 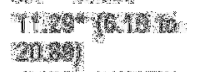 \\
\hline $\begin{array}{l}\text { Mean time at clinic } \\
\text { for doctor/nurse visit } \\
\text { (minutes) }\end{array}$ & 213.52 & $\neq$ & 231.70 & $\begin{array}{l}15.70(-4.84 \text { to } \\
36.24)\end{array}$ & 217.12 & $\begin{array}{l}10.14(-11.95 \text { to } \\
32.23\}\end{array}$ & 243.88 & $\begin{array}{l}42.05 *(20.94 \text { to } \\
63.17)\end{array}$ \\
\hline $\begin{array}{l}\text { Mean time at clinic to } \\
\text { collect ARV medication } \\
\text { (minutes) }\end{array}$ & 241.38 & $\neq$ & 169.37 & $\begin{array}{l}-72.64 *(-91.04 \\
\text { to }-54.25)\end{array}$ & 100.59 & $\begin{array}{l}-136.98 *(-157.04 \\
\text { to }-116.92)\end{array}$ & 163.04 & $\begin{array}{l}-74.47 *(-93.68 \\
\text { to }-55.26)\end{array}$ \\
\hline \multicolumn{9}{|l|}{ Whow } \\
\hline 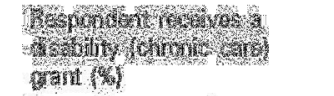 & 58 & 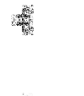 & 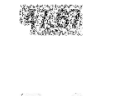 & Ther & 25 & 6row $010 \%$ & 10\% & mox \\
\hline $\begin{array}{l}\text { Expendithure on other } \\
\text { providars in past nonth } \\
\text { Wexty }\end{array}$ & $2 \pi .81$ & $\frac{1}{5}$ & 24.50 & $\left.\frac{0.22(-0.05}{0.49}\right)$ & 2175 & $-0.13(-0.426)$ & 23.69 & $\begin{array}{l}-0.01(-0.29 \\
-0.28)\end{array}$ \\
\hline 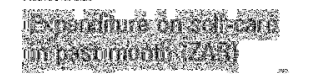 & 1010 & $\frac{G}{4}$ & Y & 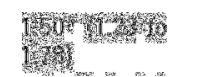 & res & $\begin{array}{l}0 \\
0\end{array}$ & 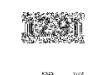 & 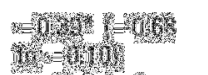 \\
\hline $\begin{array}{l}\text { Expenditure to reach and } \\
\text { during } A R T \text { facility visits } \\
\text { in part month }(Z A R)\end{array}$ & 43.76 & $\neq$ & 44.68 & $\begin{array}{l}-0.40^{*}(-0.61 \\
\text { to }-0.19\}\end{array}$ & 10.76 & $\begin{array}{l}-1.69 *(-1.92 \text { to } \\
-1.46)\end{array}$ & 8.58 & $\begin{array}{l}-1.95^{*}(-2.17 \\
\text { to }-1.73)\end{array}$ \\
\hline $\begin{array}{l}\text { Total expenditure on } \\
\text { healthcare in past month } \\
\text { (ZAR) }\end{array}$ & 95.75 & $\ddagger$ & 156.43 & $\begin{array}{l}0.31 *(0.04 \text { to } \\
0.58)\end{array}$ & 34.37 & $\begin{array}{l}-1.77 *(-2.06 \text { to } \\
-1.48)\end{array}$ & 44.92 & $\begin{array}{l}-1.68 *(-1.95 \\
\text { to }-1.40)\end{array}$ \\
\hline $\begin{array}{l}\text { Households incurring } \\
\text { healthcare costs }>10 \% \text { of } \\
\text { household expenditure (\%) }\end{array}$ & 25.60 & $\neq$ & 50.18 & $\begin{array}{l}2.94 *(2.03 \text { to } \\
4.26)\end{array}$ & 8.18 & $\begin{array}{l}0.28 * 10.16 \text { to } \\
0.50)\end{array}$ & 8.20 & $\begin{array}{l}0.27^{*}(0.16 \text { to } \\
0.45)^{\prime}\end{array}$ \\
\hline $\begin{array}{l}\text { Respondent borrowed } \\
\text { money to pay for healthcare } \\
\text { in the past month }(\%)\end{array}$ & 27.24 & $\neq$ & 36.33 & $\begin{array}{l}1.48^{*}(1.03 \text { to } \\
2.13)\end{array}$ & 1.81 & $\begin{array}{l}0.06^{*}(0.03 \text { to } \\
0.16\}\end{array}$ & $\$ 1.18$ & $\begin{array}{l}0.34^{*}\{0.21 \text { to } \\
0.55\}\end{array}$ \\
\hline \multicolumn{9}{|l|}{ Accostability } \\
\hline $\begin{array}{l}\text { Respondent agrees that } \\
\text { cusuas are too long }\{\%\}\end{array}$ & 81.41 & $\neq$ & 49.33 & $\begin{array}{l}0.20^{\circ}(0.14 \text { to } \\
0.301\end{array}$ & 65.26 & $\begin{array}{l}0.47^{*}(0.31 \text { to } \\
0.71)\end{array}$ & 67.60 & $\frac{0.54 \%(0.36 \text { to }}{0.821}$ \\
\hline $\begin{array}{l}\text { Respondent agrees that } \\
\text { some staff do not treat } \\
\text { patients with sufficient } \\
\text { irsogited ? }\end{array}$ & 28.53 & $\neq$ & 38.46 & $\begin{array}{l}1.61 \% \\
2.30\}\end{array}$ & 14.50 & $\begin{array}{l}0.43^{*}(0.27 \text { to } \\
-0.67)\end{array}$ & 16.61 & $\begin{array}{l}0.53 * 10.35 \text { to } \\
0.82)\end{array}$ \\
\hline 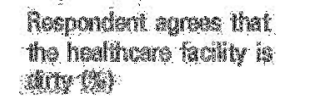 & $22: a_{4}$ & 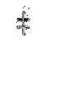 & 10.3 & $\begin{array}{l}0.62 * 70.4010 \\
0.951\end{array}$ & 11.48 & $\begin{array}{l}0,52,0.32: 30 \\
0.05 y\end{array}$ & 2586 & $\begin{array}{l}1.54 \% \text { no } \\
234\end{array}$ \\
\hline 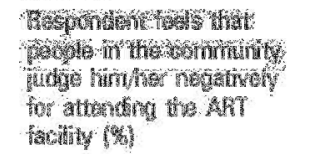 & 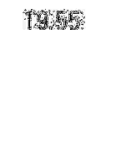 & 贸 & 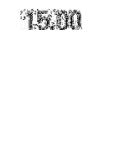 & 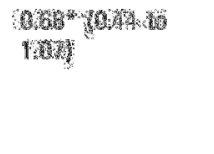 & 24 & 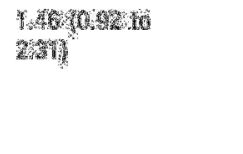 & 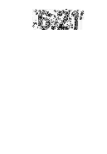 & $\begin{array}{l}\text { Wos } \\
\text { ast }\end{array}$ \\
\hline
\end{tabular}

University of the Western Cape Research Repository 


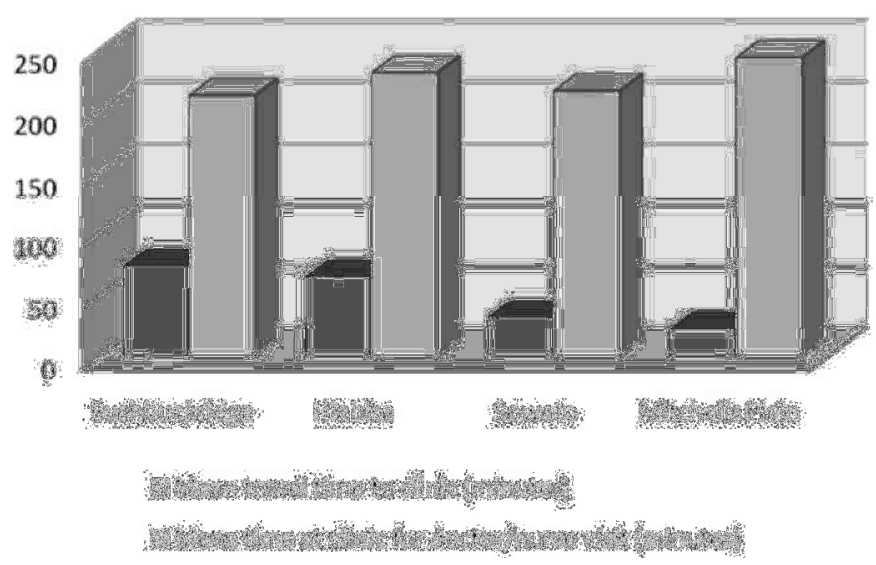

Figure 1 Time commitments associated with using antiretroviral treatment (ART) services, by site.

\begin{abstract}
Affordability
Very few respondents were in receipt of the government disability (chronic care) grant. Based on the income qualifying criteria cited earlier, $98 \%, 100 \%, 91 \%$ and $93 \%$ of respondents would qualify for the grant in Bushbuckridge, Hlabisa, Soweto and Mitchells Plain, respectively. In contrast, only $46 \%, 48 \%, 24 \%$ and $31 \%$ received it. While it may be tempting to suggest that this is an area where rural sites could be achieving more favourable access, it is also possible that access barriers are lower because both rural sub-districts include Demographic Health Surveillance sites (ie, they are the subject of long-term research and population surveillance). Given that the results of such research could be used to improve service provision, it is possible that the better access to grants in these rural sites would not be typical of other rural areas.
\end{abstract}

Total expenditure on healthcare was considerably higher in the two rural sites (see table 4 and figure 2), and respondents in these sites were also more likely to report catastrophic expenditure, defined as spending $>10 \%$ of household resources on healthcare, as well as needing to borrow money to cover healthcare expenses. While respondents in these sites spent far more on travel and other factors associated with reaching and spending time at the ART facility, particularly high levels of healthcare expenditure were attributable to spending on self-care (over the counter medicines and traditional medicines). In Hlabisa, respondents reported mean expenditure of R87.96 on self-care practices; 50\% of respondents in this site incurred catastrophic expenditure. On the other hand, there were no significant differences on spending on other providers (including private general practitioners)-with respondents in all sites spending just over R2O on this category (ranging between R21.75 in Soweto to R24.5O in Hlabisa). 


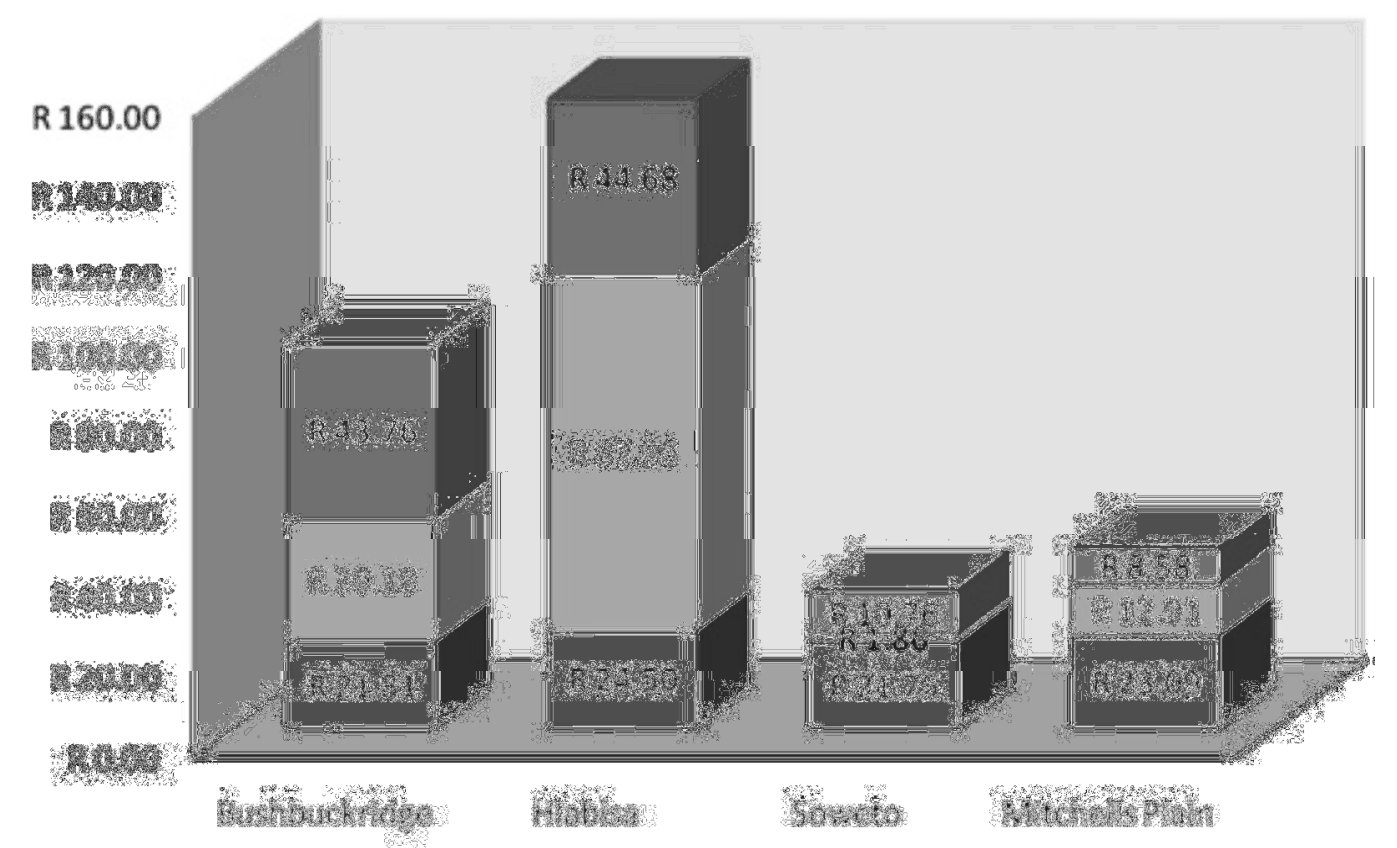

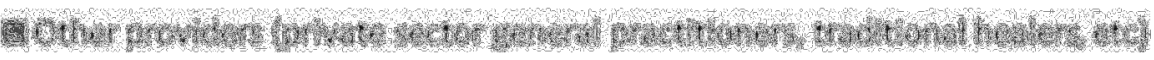

$\square$ Self-care (over the counter medicines, traditional medicines, etc)

ART facility visits (transport costs, food costs, etc)

Figure 2 Expenditure on healthcare, by site.

\section{Acceptability}

Rural/urban patterns in perceptions of the acceptability of services were less clear. Respondents in rural Bushbuckridge were considerably more likely to report that queues were too long, despite the fact that estimates of overall waiting times were similar across sites. Dirty facilities were reportedly more problematic for respondents in Bushbuckridge and Mitchells Plain, and fears of stigma ('Do you feel that people in the community judge you negatively for attending this facility for your ARV treatment?') were lower in the high coverage decentralised services of Mitchells Plain and Hlabisa. However, a higher proportion of respondents reported respectful interpersonal relationships between staff and patients in the two urban sites relative to the rural sites.

\section{DISCUSSION}

This study has assessed barriers to accessing ART services from the perspective of users interviewed in 12 facilities within two urban and two rural health sub-districts. Site-level differences in access barriers were assessed after controlling for differences in SES, duration on treatment and health status at the start of treatment. Our analysis is limited to a sample of users, and so we cannot explore which determinants of access, either individually or combined, would contribute to the failure to use ART services. Instead, in this analysis, we are concerned with inequities in the levels of barriers faced by users within different geographic locations. 
Availability access barriers to use were context specific. While the literature has suggested that rural ARTusers are likely to face higher travel times, are less likely to reach the facility by foot and are more likely to wait longer for their clinical consultations (given shortages of healthcare human resources), ${ }^{11}$ results from the Hlabisa site suggest that it is possible to mitigate these access barriers in rural areas. In this sub-district, nurse-based services are offered from all 16 primary healthcare facilities. In contrast, availability barriers were higher for ART users in Bushbuckridge across most variables assessed, where there were only two hospital-based ART service points at the time of this research. This finding provides evidence to support government's intention to offer ART from all public primary healthcare facilities in the country. 3

Although there are no user fees associated with the public sector ART programme in South Africa, the affordability barriers to access faced by rural users appear sizeable. Despite their lower SES, rural users spent more on healthcare and were more likely to report having to borrow money to cover these expenses. On the other hand, rural users had better access to the disability grant than their urban counterparts. Given the household expenditure levels reported by our respondents, the majority would qualify for this grant, receipt of which might mitigate affordability access barriers. While the model of care developed in the Hlabisa site appears to have mitigated many of the availability barriers, Hlabisa respondents fared worst in terms of affordability, and this site in addition had users with the poorest socioeconomic indicators. The biggest contributor to catastrophic expenditure in this site was spending on self-care practices-which includes over the counter medicines, vitamin supplements and traditional medicines. Reliance on self-care practices may also be associated with acceptability barriers and perceived poor quality of care-in other words, here is an example of how acceptability factors might mediate the degree of fit between patients and the health system around issues of affordability. 18

\section{Key points}

< In rural areas, key access barriers to antiretroviral treatment included the high costs of seeking care; for many respondents, these healthcare costs were catastrophic.

< Stigma was less of a concern to respondents in the two sites that had more decentralised service provision and where coverage was higher.

< Concerns about the acceptability of services could have led respondents to spend money on the use of other providers and on self-care.

< While access barriers to healthcare are multidimensional and context specific, policy-relevant solutions can be proposed through studying these barriers in diverse settings.

Other direct acceptability barriers were seen to differ across sites. While supply shortages and other organisational constraints might make it difficult for the service to reduce queues and waiting times, it is of concern that many users reported that the staff did not treat them with respect and that the services were dirty. If healthcare facilities are to function as places of 
healing, it is essential that good interpersonal relationships are developed between providers and patients ${ }^{18}$ and those patients are not exposed to potential health risks in dirty facilities.

This research has a number of limitations. First, as mentioned, we are studying access barriers in a sample of respondents who are using ART services. Access barriers are likely to be different for those who have never gained entry to the service. Second, we suggest that access barriers are likely to be context specific, and so the results from our four settings may not be generalisable to the rest of South Africa or to other countries.

\section{CONCLUSIONS}

Rural users of ART services had lower SES and on the whole faced higher access barriers than urban users. These findings are suggestive of inequitable access to ART in rural relative to urban areas. Although care is free at the point of use, affordability barriers are high. Decentralised provision, as evidenced in Hlabisa, outreach services and less frequent follow-up visits would be important policy options to mitigate access barriers to ART.

Acknowledgments We are grateful for the feedback that we received from REACH colleagues on earlier versions of this paper and would particularly like to acknowledge the patients and health workers who agreed to be involved in this project and our colleagues who contributed to the collection of these data. The data presented in this paper were collected as part of the REACH-Researching Equity in Access to Health Care-Project. The funders had no involvement in study design; in the collection, analysis and interpretation of data; in the writing of the report; and in the decision to submit the paper for publication.

Funding This work was carried out with support from the Global Health Research Initiative, a collaborative research funding partnership of the Canadian Institutes of Health Research, the Canadian International Development Agency, Health Canada, the International Development Research Centre and the Public Health Agency of Canada.

Competing interests None.

Patient consent Obtained.

Ethics approval University of Cape Town, University of Witwatersrand and University of KwaZulu-Natal.

Contributors All the authors were involved in methods development, data collection, analysis, conceptualisation and the writing of the manuscript.

Provenance and peer review Commissioned; externally peer reviewed. 


\section{REFERENCES}

1. UNAIDS. Global Report: UNAIDS Report on the Global AIDS Epidemic 2010. Geneva: Joint United Nations Programme on HIV/AIDS (UNAIDS), 2010.

2. Adam MA, Johnson LF. Estimation of adult antiretroviral treatment coverage in South Africa. $S$ Afr Med J 2009;99:661-7.

3. Republic of South Africa. Country Progress Report on the Declaration of Commitment on HIV/AIDS: 2010 Report. 2010. http://data.unaids.org/pub/Report/ 2010/southafrica_2010_country_progress_report_en.pdf (accessed 26 Oct 2011).

4. Actuarial Society of South Africa. AIDS Demographic Model 20o3lite: Actuarial Society of South Africa AIDS Committee. 2005.

5. HIV \& Aids and STI National Strategic Plan 2007-2011. Pretoria: South African National AIDS Council (SANAC), 2007.

6. Hanefeld J. How have Global Health Initiatives impacted on health equity? Promot Educ 2008;15:19-23.

7. Cleary SM, McIntyre D, Boulle AM. The cost-effectiveness of antiretroviral treatment in Khayelitsha, South Africa: a primary data analysis. Cost Eff Resour Alloc 2006;4:20. Mooney G. Is it not time for health economists to rethink equity and access? Health Econ Policy Law 2009;4:209-21.

9. McIntyre D, Thiede M, Birch S. Access as a policy-relevant concept in low- and middle-income countries. Health Econ Policy Law 2009;4:179-93.

10. Thiede M, Akweongo P, McIntyre D. Exploring the dimensions of access. In: McIntyre D, Mooney G, eds. The Economics of Health Equity. Cambridge: Cambridge University Press, 2007.

11. Posse M, Meheus F, van Asten $\mathrm{H}$, et al. Barriers to access to antiretroviral treatment in developing countries: a review. Trop Med Int Health 2008;13:904-13.

12. Braveman P. Health disparities and health equity: concepts and measurement. Annu Rev Public Health 2006;27:167-94.

13. Ranson MK. Reduction of catastrophic health care expenditures by a community- based health insurance scheme in Gujarat, India: current experiences and challenges. Bull World Health Organ 2002;80:613-21.

14. Lauritsen J, Bruus M. EpiData (version 3). A Comprehensive Tool for Validated Entry and Documentation of Data. Odense, Denmark: The EpiData Association, 2003-2004.

15. Montgomery MR, Gragnolati M, Burke KA, et al. Measuring living standards with proxy variables. Demography 2000;37:155-74.

16. Booysen F, Van Der Berg S, Burger R, et al. Using an asset index to assess trends in poverty in seven sub-Saharan African countries. World Dev 2008;36:1113-30.

17. Howe LD, Hargreaves JR, Huttly SR. Issues in the construction of wealth indices for the measurement of socio-economic position in low-income countries. Emerg Themes Epidemiol 2008;5:3.

18. Gilson L. The Relevance of Healthwords to Health System Thinking About Access. 
